\title{
COVID-19: EXTRAPULMONARY IMPAIRMENTS (OWN DATA OF INFECTION HOSPITAL OF FSBI FSSCC FMBA OF RUSSIA) AND EXPERIENCE OF USE DIFFERENT PROFILE SPECIALISTS TO WORKING IN HOSPITALS
}

\author{
Abramov VG, Gaygolnik TV, Fetisov AO, Pinzhina VN, Osipova TM, Bezdenezhnykh AF, Morozov DN \\ Federal State Financed Institution Federal Siberian Research Clinical Centre, Federal Medical-Biological Agency of Russia
}

\begin{abstract}
The article dwells upon the identification of extrapulmonary manifestations of COVID-19 using a time-saving, questionnaire specially designed by the authors to be filled out by the patients themselves. The introduction: sets out the relevance of exploratory studies of extrapulmonary lesions of this disease, identifies the main links in the pathogenesis of extrapulmonary lesions, and theoretically identifies possible targets in the body. It also includes the data, available in the literature at present, on the causative agent COVID-19 and other coronaviruses. Potential targets (in addition to the lungs) can be the nervous, digestive, cardiovascular and urinary systems, and the skin. The materials and methods: describe the questionnaire itself, its subdivision into domains, and include the data on the patient population. The results and discussion section sets out the researchers' own data. The most common symptoms in patients are apathy and asthenia, febrile syndrome, and respiratory symptoms. Formally, lesions of the nervous and digestive systems, as well as cardiovascular events, are less common. However, with a slight change in the counting technique (including apathy, asthenia and headache into it), the prevalence of neurological manifestations approaches $97.75 \%$, and becomes the first in occurrence frequency rating. Symptoms indicating involvement of kidneys and skin were significantly less common. On the one hand, with the appearance of more severe cases of the disease, this percentage should increase, and on the other hand, its identification by the method of questioning in more severe patients is less important, especially since the main vital indicators of such patients are monitored. Conclusions: the authors outline directions for further search activity (confirmation of the data obtained by the results of laboratory and instrumental examinations, studying the connection to the therapy) and medical care organization for patients with COVID-19 (including particular specialists in the teams of infectious hospitals during the rise in the incidence and transition to counseling conducted by the specialists as the incidence subsides in the future)
\end{abstract}

Keywords: COVID-19, extrapulmonary manifestations, neurological lesions, pain syndromes, gastroenterological symptoms, apathy and asthenia, hyposmia, medical care organization

Received: 09.07.2020 Accepted: 13.08.2020 Published online: 22.09.2020

DOI: $10.47183 /$ mes.2020.013

\section{COVID-19: ВНЕЛЕГОЧНЫЕ ПРОЯВЛЕНИЯ У ПАЦИЕНТОВ (СОБСТВЕННЫЕ ДАННЫЕ ИНФЕКЦИОННОГО ГОСПИТАЛЯ ФГБУ ФСНКЦ ФМБА РОССИИ)}

\author{
В. Г. Абрамов, Т. В. Гайгольник, А. О. Фетисов, В. Н. Пинжина, Т. М. Осипова, А. Ф. Безденежных, Д. Н. Морозов
}

ФГБУ «Федеральный Сибирский научно-клинический центр Федерального медико-биологического агентства», г. Красноярск, Россия

\begin{abstract}
Введение: статья посвящена вопросам выявления внелегочных проявлений COVID-19 с использованием малозатратной по времени, специально разработанной для этой цели авторами анкетой, заполняемой самим пациентом. Материалы и методы: всего в исследование было включено 93 пациента, выразивших готовность сотрудничать. Анкета, включает в себя демографические данные (пол, возраст), 3 вопроса, касающихся симптомов, беспокоящих пациента в открытой (свободной форме), и 92 вопроса, указывающих на симптом в закрытой форме (пациент в случае наличия симптома должен был поставить галочку в соответствующем окошке). Фактически все симптомы (перечисленные в закрытом блоке) можно классифицировать на 9 больших доменов (групп): болевые, лихорадочные, респираторные, неврологические, гастроэнтерологические, дерматологические, нефроурологические, кардиологические, и отдельно выделена группа апатии и астении. Результаты и обсуждение: наиболее распространенными симптомами у пациентов являются апатия и астения, лихорадочный синдром, респираторные явления. Формально, несколько меньшую распространенность имеют поражение нервной и пищеварительной систем, а также сердечно-сосудистые явления. Однако, при небольшом изменении методики подсчета (включение апатии, астении и головной боли), распространенность неврологических проявлений приближается к 97,75\%, и выходит на первое место. Симптомы, указывающие на вовлечение почек и кожи, имели существенно меньшую распространенность. Выводы: подавляющее большинство пациентов имеют внелегочные проявления заболевания. Авторами намечены направления для дальнейшей поисковой активности (подтверждение полученных данных результатами лабораторных и инструментальных обследований, изучение связи с проводимой терапией) и организации медицинской помощи пациентам c COVID-19 (включение разнопрофильных узких специалистов в состав бригад инфекционных госпиталей во время подъема заболеваемости и переход к консультированию узкими специалистами по мере спадания заболеваемости в дальнейшем).
\end{abstract}

Ключевые слова: COVID-19, внелегочные проявления, неврологические поражения, болевые синдромы, гастроэнтерологические симптомы, апатия и астения, гипосмия, организация медицинской помощи

Статья получена: 09.07.2020 Статья принята к печати: 13.08.2020 Опубликована онлайн: 22.09.2020

DOI: $10.47183 /$ mes.2020.013

\section{Introduction}

The novel coronavirus disease (COVID-19) first reported in December 2019 has rapidly become a global public health emergency. Pneumonia and acute respiratory distress syndrome are commonly observed serious clinical manifestations of COVID-19. According to WHO, by mid-June 2020 over 6 million people worldwide had contracted the infection. The number of publications on the clinical course, diagnosis and therapy of COVID-19-induced pneumonia continues to grow. Yet little is known about the long-term effects of the infection on the respiratory tract. Even more understudied are the extrapulmonary complications of COVID-19. At the time of writing, there was very little information on the extra-pulmonary presentations of the disease; the scarce available data came from mass media sources, single clinical case reports or small-scale observational studies conducted in China and the European Union. At that time, there were no robust data representing the Russian population.

Coronaviruses use their spike proteins (SP) to bind to a receptor on the host cell membrane. At least 3 receptors are known that mediate the invasion, including the angiotensinconverting enzyme 2 (ACE2) [1], dipeptidyl peptidase 4 (DPP4) [2] and CD147 [3]. Once the virus latches onto its target, it 
fuses with the host cell membrane and its RNA enters the cytoplasm for subsequent translation and protein replication. The tropism of the coronavirus is determined by the expression of the aforementioned receptors in different organs [4]. This means that damage inflicted by coronaviruses is not limited to the respiratory tract: the central nervous system (CNS) can also be attacked $[5,6,7]$.

Once SARS-CoV-2, the causative agent of COVID-19, enters the bloodstream, it can cross the blood-brain barrier and spread to CNS. Another possible route of infection is via the olfactory bulb: the virus spreads to CNS by moving along the axons that course though the lamina cribrosa. There is experimental evidence that the mouse hepatitis virus (MHV), another representative of the Coronaviridae family, attacks CNS following the intranasal challenge. In an experiment conducted by Perlman S. et al. in 1990, surgical ablation of the olfactory pathway prior to nasal inoculation with MHV prevented CNS infection. Interestingly, SARS-CoV RNA was detected postmortem in the brain tissue of 8 patients who died of atypical pneumonia in the early 2000 s $[5,6,7]$.

There are other entry points the virus can use to infect CNS. ACE2 is a defense factor for the cardiovascular system and the brain; it is found in many organs, including the nervous system and skeletal muscles, and plays the central role in regulating arterial blood pressure [8]. By binding to ACE2, viruses can cause elevated blood pressure and promote the risk of cerebral hemorrhages. Considering that the spike protein of SARSCov-2 is capable of interacting with ACE2 expressed in the capillary endothelium, the virus can attack the vascular system, breach the blood-brain barrier and invade CNS [4].

Neurological symptoms of COVID-19 are not limited to CNS, but can also develop in the peripheral nervous system (PNS). Impaired consciousness and other symptoms of brain damage are predictors of a very poor prognosis: $22 \%$ of non-survivors with COVID-19 vs. $1 \%$ of survivors had impaired consciousness [9]. Headache, dizziness, impaired consciousness, ataxia, acute cerebrovascular events, and seizures were the main clinical signs of neurological (CNS) damage observed in 53 of 218 (24.8\%) Chinese patients with COVID-19. On the other hand, PNS involvement was observed in 19 patients (8.9\%) in that cohort; hyposmia and dysgeusia were the most common symptoms affecting 11 (5.1\%) and 12 (5.6\%) patients, respectively.

A study conducted in a European population [10] reported hyposmia in $85.6 \%$ of patients with or without nasal congestion; $88 \%$ of patients had dysgeusia. In the short term, only $44 \%$ of patients recovered the sense of smell. Indeed, every systemic infection can cause damage to CNS or PNS, but this is also the reason why these phenomena need to be thoroughly studied.

In patients with COVID-19, distortion of the sense of smell or taste might arise from both CNS or PNS damage, requiring further investigation. The hypothesis about the loss of olfaction being the early symptom of the novel coronavirus infection is highly controversial. In 2006, there was a clinical case report of complete anosmia set in 3 weeks after the onset of the first SARS-CoV symptom. The patient was a 26-year-old female. She developed complete bilateral anosmia after her upper respiratory tract condition started to improve. This might indicate progression to chronic infection (persistence of the virus?) or delayed damage resulting from the activation of the immune system.

There are reports of 3 encephalitis cases associated with COVID-19. In one study, SARS-Cov-2 was detected in a patient's cerebrospinal fluid [11], suggesting that encephalitis was not the result of the immune response to infection.
Similarly, Moriguchi T. et. al (2020) reported a case of meningitis/ encephalitis, in which SARS-Cov-2 RNA was not detected in the nasopharyngeal swab of a patient but was present in the cerebrospinal fluid. The cerebrospinal fluid test was ordered because prior to that a CT scan had revealed ground glass opacities in the patient's lungs, which is a relatively specific sign of COVID-19 [12]. Another neurological manifestation of a coronavirus infection is acute disseminated encephalomyelitis (ADEM) [13].

Almost $40 \%$ of patients infected with the novel coronavirus suffer from headache, impaired consciousness and other symptoms of brain dysfunction. On autopsies, brain edema is a common finding in COVID-19 patients [7]. Therefore, it can be hypothesized that COVID-19 causes toxic encephalopathy.

With SARS-Cov-2, there is a potential risk of chronic CSN infection. CNS has a dense parenchyma and normally the blood-brain barrier can protect it from viral invasion. However, once the virus has entered CNS, its elimination becomes a challenge for the immune system [14]. Due to the lack of MHC in CNS, elimination of the virus in nerve cells is performed by cytotoxic T cells or through neuronal apoptosis. Besides, some aspects of nerve cell homeostasis also foster the survival of the virus [14]. Elimination of the virus through neuronal apoptosis raises a question about the long-term effects and potential risks of neurodegenerative conditions that develop independently of or are associated with chronic CNS damage induced by the coronavirus.

A cytokine storm in response to infection is the immunological aspect of CNS invasion by the coronavirus; a cytokine storm can provoke acute cerebrovascular events [9, 15]. Patients with severe COVID-19 have elevated D-dimer and a low platelet count, which makes these patients susceptible to vascular catastrophes [3].

The effect of the coronavirus on PNS was described in a number of studies. For example, Zhao H. [16] discovered an association between the Guillain-Barre syndrome (GBS) and COVID-19. A 61-year-old female presented with complaints of acute weakness in both legs and fatigue. Remarkably, acute respiratory symptoms appeared 7 days afterwards. Her nasopharyngeal swabs were positive for SARS-Cov-2 (RT-PCR) [16]. It Italy, 5 individuals infected with the novel coronavirus developed GBS; nasopharyngeal swabs were positive for COVID in 4 out of 5 individuals at the time of GBS manifestations. Later, COVID-19 was serologically confirmed in all of those patients. PCR tests did not detect the virus in their cerebrospinal fluid. Time from the first symptoms of the coronavirus infection to the onset of GBS symptoms was 5 to 10 days, i.e. similar to other infections also leading to GBS [17]. Besides, 2 cases of the Miller-Fisher syndrome were reported in COVID-19 patients, who developed ophthalmoplegia, ataxia and areflexia [18]

Summing up, the following CNS pathology may be associated with COVID-19:

1. encephalitis (meningoencephalitis?) caused directly by the virus;

2. toxic encephalopathy;

3. cerebrovascular complications (stroke, TIA);

4. demyelinating disorders (ADEM);

The following PNS pathology can develop following SARSCoV-2 infection:

1. Guillain-Barre syndrome;

2. Miller-Fisher syndrome.

Possible routes of infection include:

1. direct invasion of the nervous tissue (the olfactory route);

2. through the bloodstream by crossing the blood-brain barrier. 
Possible mechanisms underlying CNS/PNS damage include:

1. direct cytopathic effect of the virus;

2. hypoxia (in severe cases);

3. cytokine storm;

4. changes in blood rheology and blood coagulation properties leading to a cerebrovascular catastrophe;

5. damage by acute phase antibodies;

6. damage by activated macrophages and microglia cells involved in chronic inflammation;

7. changes in arterial blood pressure as a result of the virus binding to ACE2, followed by a cerebrovascular catastrophe.

As mentioned above, the virus has tropism for any tissue expressing ACE2, therefore, it can cause damage to the intestine [19] and heart [20, 6, 21]. ACE2 is predominantly expressed in the lungs (alveolar type 2 cells), hepatic cholangiocytes, the large intestine, esophagus, ileum, and rectum, gastric epithelial cells, and proximal tubules of the kidney. Some patients develop signs of kidney/liver failure, which suggests that COVID-19 can affect these organs, too. There has been a report of collapsing glomerulopathy in a COVID-19 patient [22]. By analyzing the accumulated data, researchers were able to identify the organs at risk, including the lungs, heart, esophagus, kidneys, bladder, and ileum, and a few vulnerable cell types, including alveolar type 2 and myocardial cells, cells of the proximal tubules, ileal and esophageal epithelium, urothelial cells of the bladder. In a study conducted in 204 patients with confirmed COVID-19 undergoing treatment in Hubei hospitals (China), 99 patients (48.5\%) had gastrointestinal complaints in the absence of respiratory symptoms [19]. There has been a lot of discussion on the interactions between the microbiota and the immune system and its effects on pro- and anti-inflammatory factors. The "gut-brain axis" has become a widely recognized term, and the role of microbiota in multiple sclerosis has been proved [23].

Today, there is evidence suggesting the existence of the gutlung axis [24]. Presumably, the gut-lung axis is bidirectional, i.e. endotoxins and microbial metabolites can exert their effects on the lungs through blood and, in turn, inflammation in the lungs can affect the gut microbiota [25]. Hypothetically, SARS-Cov2 might have an effect on the gut microbiota. In fact, some studies have demonstrated a link between respiratory infections and changes in the gut microbiota composition. It would be only natural and logical to hypothesize that all complications and forms of COVID-19 might depend on the gut microbiota and that the virus can and does provoke gastrointestinal symptoms.

\section{Materials and methods}

Considering the abovesaid, it was only logical to study the actual prevalence of various symptoms in patients with COVID-19 admitted to the hospital for infectious diseases of the Federal Siberian Research Clinical Center (FMBA, Russia). A questionnaire was designed to collect patients' demographic data (age, sex), free-form answers to 3 open-ended questions and answers to 92 tick-a-box closed-ended questions about possible complaints and symptoms. All symptoms listed in the closed-ended section of the questionnaire can be classified into 9 major domains (groups): pain, febrility, respiratory symptoms, neurological symptoms, digestive symptoms, skin symptoms, renal and urological symptoms, cardiac symptoms, apathy and asthenia. Many of the symptoms were listed in duplicates; for example, a patient could select from "increased body temperature", "fever" and "chills" in the febrility domain. This was done on purpose because patients could use different semantic structures to describe their condition. Questions from other groups were presented in a similar fashion. The study was approved by the Local Ethics Committee. Hospitalized patients who gave consent to participate received questionnaires in May through June 2020. The study recruited 93 patients. In 4 cases, some of the questions in the questionnaires were skipped, so those questionnaires were excluded from the analysis. Women accounted for $64.04 \%$ (57) of the participants and men, for $35.96 \%$ (32). The mean age was $50.80 \pm 13.55$ years; the youngest participant was 20 years old; the oldest, 94 years old. The questionnaires were filled out at different time points from the onset of the disease. The "earliest" questionnaire was completed on the day of onset, the latest, on day 35. On average, the period between the onset of the disease and questionnaire completion was $15.55 \pm 9.96$ days.

\section{Results and discussion}

Considering that some symptoms from the closed-ended section overlapped, the most interesting part of the analysis was not the total score itself (in all domains or in one domain),

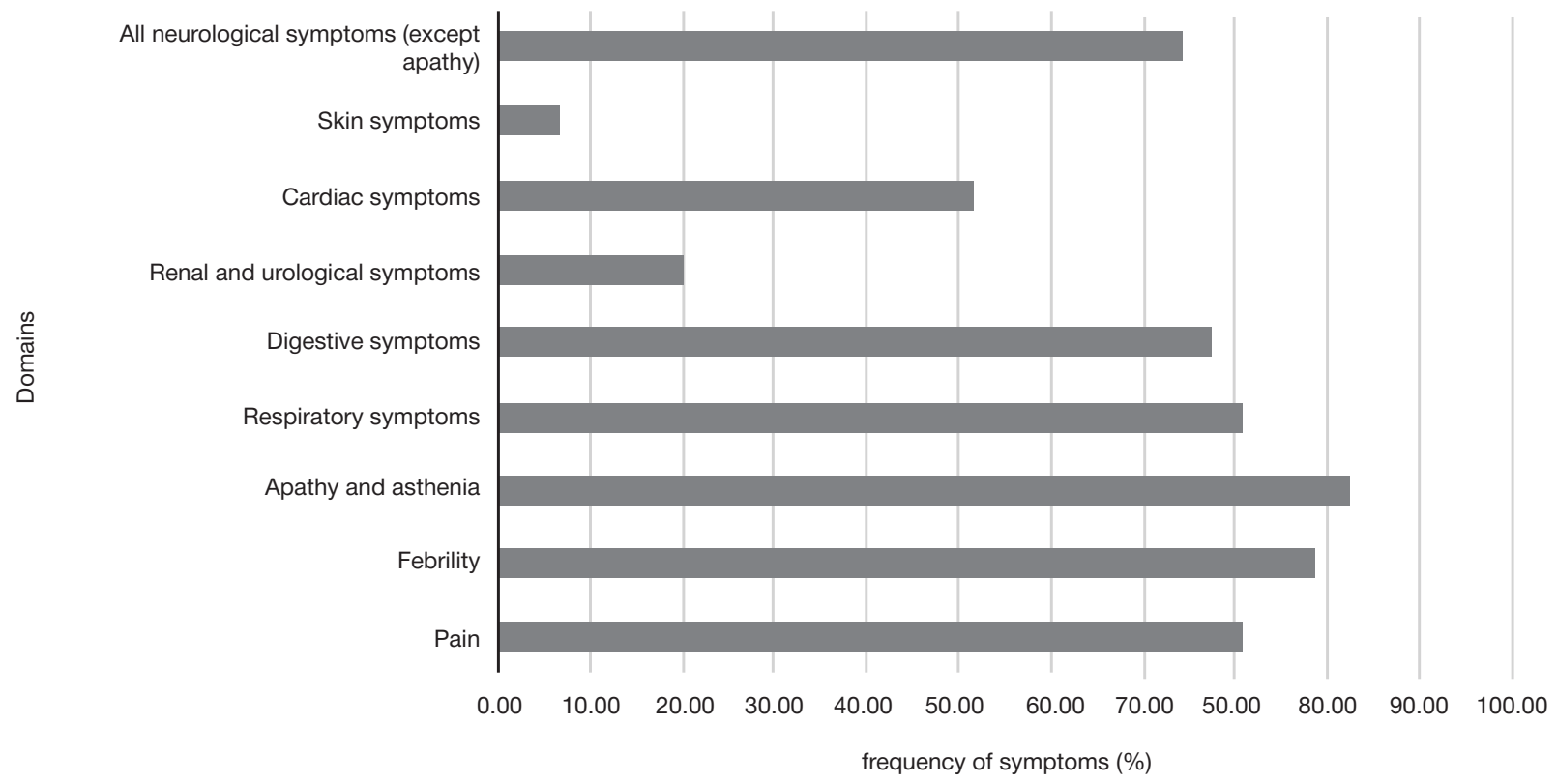

Fig. 1. The prevalence of symptoms from different domains 
since the total number of positive answers does not necessarily suggest the severity of the condition, but the prevalence of symptoms from each domain. If a patient put a tick against at least one symptom listed in a group of symptoms, he/she was considered positive for this group of symptoms. The results are provided in Fig. 1.

The bar chart shows that the most common symptoms were apathy and asthenia (92.13\%). These symptoms cannot be explained by febrility only because febrile manifestations were less frequent. Perhaps, other factors might be in play here, including the effect of the virus on CNS and the psychoemotional response of the patient. Fever ranked second (88.76\%), referring to any increase in body temperature, including subfebrile, which is a common manifestation of infection. Pain and respiratory symptoms ranked third $(80.90 \%$ for both), followed by digestive (77.53\%), neurological (74.16\% excluding apathy, asthenia and headache), cardiac (51.69\%), renal and urological (20.22\%), and skin (6.74\%) symptoms.

Compositionally, the asthenia and apathy domain was dominated by weakness (83.15\%), followed by inertia (47.19\%) and apathy (41.57\%).

The febrility domain was dominated by febrile chills (55.06\%).

The pain domain was dominated by headache $(48.31 \%)$, indirectly suggesting CNS damage, chest pain (38.20\%), which can be explained by the pulmonary manifestations of the disease, and myalgia (35.96\%), which implies intoxication and/ or an immune system reaction. There were a few interesting findings: Ioin pain $(16.85 \%)$, which raises concerns about the possibility of kidney damage, subcostal pain on the ride side (11.24\%) (liver damage?) and stomach pain (19.10\%) (intestinal involvement?). In our future studies, we will attempt to retrospectively analyze possible correlations between these symptoms and the results of laboratory tests.

The respiratory domain was dominated by cough (55.06\%), labored breathing (35.96\%) and shortness of breath (30.34\%). Interestingly, nasal cold (11.24\%) was much less frequent than hyposmia (40.45\%). This proves the predominantly neurogenic origin of hyposmia.

In the digestive domain, nonspecific symptoms were the most prevalent, including poor appetite (53.93\%) and nausea $(40.45 \%)$. Vomiting was present in $24.72 \%$ of patients. These figures suggest damage to the gastrointestinal tract hypothesized in previous research studies. Diarrhea was observed in $28.09 \%$ of patients, whereas bloating, in $19.10 \%$. These symptoms might indicate the involvement of the gut microbiota or the intestine. Jaundice was reported in $4.49 \%$, cases, while bitter taste in the mouth, in $20.22 \%$, possibly indicative of liver damage. Currently, the authors are researching a possible correlation between these symptoms and the received therapy.

Table 1. Neurological symptoms (excluding apathy, asthenia and headache)
Special consideration should be given to neurological symptoms (see Table 1).

The table shows that olfactory and gustatory impairments (46.07\%) are typical and widely-spread symptoms of COVID-19. Affective disorders (38.20\%) and cognitive impairment (31.46\%) are also common.

Other symptoms are significantly less frequent, but on the whole, they confirm the possibility of damage to ACE2-expresing structures, the brain stem in particular (the cytopathic effect of the virus?), and to peripheral structures (immune-mediated damage?). Notably, the total frequency of nervous system damage, without apathy, asthenia and headache is $74.16 \%$; with these 3 symptoms included, the figure is $97.75 \%$. Thus, neurological damage may be the leading complication of the disease in terms of frequency but not severity, depending on how the symptoms are distributed between different symptom domains.

Considering the pathogenesis of the disease, cardiac symptoms are unsurprisingly mainly represented by elevated blood pressure (24.72\%) and tachycardia (20.22\%). In 13.48\% of cases, patients had a subjective sensation of cardiac pathology. Further research is needed to objectively confirm the underlying cause of the complaints and to evaluate the effect of therapeutic interventions. Low blood pressure was reported in $13.48 \%$ of cases. This might indicate autonomic dysfunction, which again brings up the question of the real prevalence of neurological symptoms in patients with COVID-19.

Among nephrological symptoms, the most prevalent were frequent urination $(14.61 \%)$, difficulty urinating (4.49\%) and painful urination $(2.25 \%)$. On the whole, these symptoms were not so common. Likewise, in the skin domain, cyanosis or hyperemia were present in $4.49 \%$ of cases. Bruises, petechiae and the like were absent, which indirectly suggests the adequacy of the chosen regimen for supporting normal blood rheology and coagulation properties. However, as the number of severe patients grows, the proportion of renal/urological and skin symptoms might also increase.

The answers in the open-ended section of the questionnaire were systematized. Not in all cases, though, the sematic structures used by the patients to describe their condition allowed us to categorize the most nagging symptom ( for example, "the simultaneous and extremely strong effect of all symptoms"). Approximately in $47.14 \%$ cases, febrility was reported as the most bothersome symptom. Weakness ranked second (14.29\%), followed by pain and shortness of breath (11.43\%). Other symptoms were less frequent. However, 2 patients specified nausea and 1 reported diarrhea as very distressing, which suggests the importance of these symptoms for the patients.

It was difficult for the patients to describe their complaints in an open-ended part of the questionnaire, which speaks in favor

\begin{tabular}{|l|c|}
\hline \multicolumn{1}{|c|}{ Symptoms and possibly affected structures } & Frequency, \% \\
\hline Dysgeusia and hyposmia (olfactory and gustatory analyzers) & 46.07 \\
\hline Motor symptoms (localized weakness, transient facial asymmetry) (pyramidal tracts, peripheral nerves) & 26.97 \\
\hline Extrapyramidal symptoms (predominantly tremor) (basal ganglia) & 13.48 \\
\hline Visual impairment, oculomotor symptoms (CN II, III, IV, VI and midbrain structures) & 13.48 \\
\hline Auditory impairment (CN VIII, cochlear branch) & 12.36 \\
\hline Impaired coordination (ataxia) (CN VIII, vestibular branch, cerebellum, its connections, proprioceptive pathways) & 31.46 \\
\hline Bulbar disorders: dysarthria, dysphagia (CN IX, X) & 4.49 \\
\hline Sensory disorders, hypesthesia, paresthesia, cramps (brain stem, peripheral nerves) & 16.85 \\
\hline Affective disorders (irritability, anxiety, sleep disorders, depression) (limbic system) & 38.20 \\
\hline Cognitive impairment (attention or memory deficit, disorientation, sensory or motor aphasia) (cortex and its connections) & 14.61 \\
\hline
\end{tabular}


of using closed-ended questions as a rapid and effective tool for assessing the symptoms of the disease.

\section{CONCLUSIONS}

We conclude that for the majority of patients, especially for those with severe disease, respiratory complications (pulmonary, in particular) were the most threatening. However, most of our patients also had extrapulmonary symptoms. Apathy, asthenia pain, digestive and neurological manifestations were the most common, followed by cardiovascular symptoms. Less often, the virus can cause damage to other organs and tissues. The medical staff providing care to patients with COVID-19 must be competent in identifying extrapulmonary symptoms of the disease. he fact that a lot of non-infectious disease specialists have been retrained to provide medical care to COVID-19 patients can be regarded as an advantage since it creates an opportunity to obtain valuable consultations on the extrapulmonary manifestations of the infection from an experienced specialist. When the epidemiologic situation improves and the number of infected individuals goes down, so will the hospital bed occupancy by COVID-19 patients and the number of medical personnel involved in delivering COVID19-oriented care. Therefore, new approaches will be needed to provide consultations to such patients.

The authors believe that long-term sequelae of COVID-19, both pulmonary and extrapulmonary, need to be thoroughly studied. The majority of our patients were willing to participate in further research. This encouraged us to apply for a Russian Foundation for Basic Research Grant (Id 20-04-60548) to sponsor the project on the evaluation of the long-term effects of pulmonary and extrapulmonary (neurological, gastrointestinal, nephrological, and immunological) complications of COVID-19 considering the effect of the gut microbiota, their mathematical modeling, prediction and ways to minimize the inflicted damage. We also believe that raising awareness of the extrapulmonary symptoms of COVID-19 in healthcare workers specializing in different medical fields will improve the efficacy of medical care for in-and outpatients and ensure timely detection of individuals presenting with extrapulmonary symptoms of COVID-19.

\section{References}

1. Hoffmann M. et al. SARS-CoV-2 cell entry depends on ACE2 and TMPRSS2 and is blocked by a clinically proven protease inhibitor //Cell. - 2020.

2. Raj V. S. et al. Dipeptidyl peptidase 4 is a functional receptor for the emerging human coronavirus-EMC //Nature. - 2013. - T. 495. - №. 7440. - C. 251-254.

3. Wang $\mathrm{K}$. et al. SARS-CoV-2 invades host cells via a novel route CD147-spike protein //BioRxiv. - 2020.

4. Baig A. M. Neurological manifestations in COVID-19 caused by SARS-CoV-2 //CNS neuroscience \& therapeutics. - 2020. - T. 26. - №. 5. - C. 499.

5. Ding $Y$. et al. Organ distribution of severe acute respiratory syndrome (SARS) associated coronavirus (SARS-CoV) in SARS patients: implications for pathogenesis and virus transmission pathways //The Journal of Pathology: A Journal of the Pathological Society of Great Britain and Ireland. - 2004. - T. 203. - №. 2. - C 622-630.

6. Gu J. et al. Multiple organ infection and the pathogenesis of SARS //Journal of Experimental Medicine. - 2005. - T. 202. - №. 3. - C. 415-424.

7. Xu X. et al. Clinical findings in a group of patients infected with the 2019 novel coronavirus (SArS-Cov-2) outside of Wuhan, China: retrospective case series BMJ, 368 (2020), p. m606

8. Miller A. J., Arnold A. C. The renin-angiotensin system in cardiovascular autonomic control: recent developments and clinical implications //Clinical Autonomic Research. - 2019. - T. 29. - №. 2. - C. 231-243.

9. Chen T. L. et al. Clinical characteristics and outcomes of older patients with coronavirus disease 2019 (COVID-19) in Wuhan, China (2019): a single-centered, retrospective study //The Journals of Gerontology: Series A. - 2020.

10. Lechien J. R. et al. Olfactory and gustatory dysfunctions as a clinical presentation of mild-to-moderate forms of the coronavirus disease (COVID-19): a multicenter European study //European Archives of Oto-Rhino-Laryngology. - 2020. - C. 1-11.

11. Zhou L. et al. Sars-Cov-2: Underestimated damage to nervous system //Travel Med Infect Dis. - 2020. - T. 101642. - №. 10.1016.

12. Moriguchi T. et al. A first case of meningitis/encephalitis associated

with SARS-Coronavirus-2 //International Journal of Infectious Diseases. - 2020

13. Yeh E. A. et al. Detection of coronavirus in the central nervous system of a child with acute disseminated encephalomyelitis // Pediatrics. - 2004. - T. 113. - №. 1. - C. e73-e76.

14. Reinhold A.K., Rittner H.L Barrier function in the peripheral and central nervous system - a review Pflugers Arch, 469 (2017), pp. 123-134

15. Mehta P. et al. COVID-19: consider cytokine storm syndromes and immunosuppression //Lancet (London, England). - 2020. - T. 395. - №. 10229. - C. 1033.

16. Zhao $H$. et al. Guillain-Barré syndrome associated with SARSCoV-2 infection: causality or coincidence? //The Lancet Neurology. - 2020. - T. 19. - №. 5. - C. 383-384.

17. Toscano G. et al. Guillain-Barré syndrome associated with SARSCoV-2 //New England Journal of Medicine. - 2020.

18. Gutiérrez-Ortiz C. et al. Miller Fisher Syndrome and polyneuritis cranialis in COVID-19 //Neurology. - 2020.

19. Leung W. K. et al. Enteric involvement of severe acute respiratory syndrome-associated coronavirus infection //Gastroenterology. 2003. - T. 125. - №. 4. - C. 1011-1017.

20. Dimitrov D. S. The secret life of ACE2 as a receptor for the SARS virus //Cell. - 2003. - T. 115. - №. 6. - C. 652-653.

21. Oudit G. Y. et al. SARS-coronavirus modulation of myocardial ACE2 expression and inflammation in patients with SARS // European journal of clinical investigation. - 2009. - T. 39. - №. 7. - C. 618-625

22. Kissling S. et al. Collapsing glomerulopathy in a COVID-19 patient //Kidney International. - 2020.

23. Kozhieva M.H. i dr. Human intestinal microbiota and multiple sclerosis // Journal of Neurology and Psychiatry. SS Korsakova. Special issues. - 2017. - T. 117. - No. 10. - S. 11-19.

24. Keely S. et al. Activated fluid transport regulates bacterial-epithelial interactions and significantly shifts the murine colonic microbiome //Gut microbes. - 2012. - T. 3. - №. 3. - C. 250-260.

25. Dumas $A$. et al. The role of the lung microbiota and the gut-lung axis in respiratory infectious diseases //Cellular microbiology. 2018. - T. 20. - №. 12. - C. e12966 


\section{Литература}

1. Hoffmann M. et al. SARS-CoV-2 cell entry depends on ACE2 and TMPRSS2 and is blocked by a clinically proven protease inhibitor //Cell. - 2020.

2. Raj V. S. et al. Dipeptidyl peptidase 4 is a functional receptor for the emerging human coronavirus-EMC //Nature. - 2013. - T. 495. - №. 7440. - C. 251-254.

3. Wang K. et al. SARS-CoV-2 invades host cells via a novel route: CD147-spike protein //BioRxiv. - 2020.

4. Baig A. M. Neurological manifestations in COVID-19 caused by SARS-CoV-2 //CNS neuroscience \& therapeutics. - 2020. - T. 26. - №. 5. - C. 499.

5. Ding $Y$. et al. Organ distribution of severe acute respiratory syndrome (SARS) associated coronavirus (SARS-CoV) in SARS patients: implications for pathogenesis and virus transmission pathways //The Journal of Pathology: A Journal of the Pathological Society of Great Britain and Ireland. - 2004. - T. 203. - №. 2. - C. 622-630.

6. Gu J. et al. Multiple organ infection and the pathogenesis of SARS //Journal of Experimental Medicine. - 2005. - T. 202. - №. 3. - C. 415-424.

7. Xu X. et al. Clinical findings in a group of patients infected with the 2019 novel coronavirus (SArS-Cov-2) outside of Wuhan, China: retrospective case series BMJ, 368 (2020), p. m606

8. Miller A. J., Arnold A. C. The renin-angiotensin system in cardiovascular autonomic control: recent developments and clinical implications //Clinical Autonomic Research. - 2019. - T. 29. - №. 2. - C. 231-243.

9. Chen T. L. et al. Clinical characteristics and outcomes of older patients with coronavirus disease 2019 (COVID-19) in Wuhan, China (2019): a single-centered, retrospective study //The Journals of Gerontology: Series A. - 2020.

10. Lechien J. R. et al. Olfactory and gustatory dysfunctions as a clinical presentation of mild-to-moderate forms of the coronavirus disease (COVID-19): a multicenter European study //European Archives of Oto-Rhino-Laryngology. - 2020. - C. 1-11.

11. Zhou L. et al. Sars-Cov-2: Underestimated damage to nervous system //Travel Med Infect Dis. - 2020. - T. 101642. - №. 10.1016.

12. Moriguchi T. et al. A first case of meningitis/encephalitis associated with SARS-Coronavirus-2 //International Journal of Infectious Diseases. - 2020

13. Yeh E. A. et al. Detection of coronavirus in the central nervous system of a child with acute disseminated encephalomyelitis // Pediatrics. - 2004. - T. 113. - №. 1. - C. e73-e76.

14. Reinhold A.K., Rittner H.L Barrier function in the peripheral and central nervous system - a review Pflugers Arch, 469 (2017), pp. 123-134

15. Mehta P. et al. COVID-19: consider cytokine storm syndromes and immunosuppression //Lancet (London, England). - 2020. - T. 395. - №. 10229. - C. 1033.

16. Zhao $\mathrm{H}$. et al. Guillain-Barré syndrome associated with SARSCoV-2 infection: causality or coincidence? //The Lancet Neurology. - 2020. - T. 19. - №. 5. - C. 383-384.

17. Toscano G. et al. Guillain-Barré syndrome associated with SARSCoV-2 //New England Journal of Medicine. - 2020.

18. Gutiérrez-Ortiz C. et al. Miller Fisher Syndrome and polyneuritis cranialis in COVID-19 //Neurology. - 2020.

19. Leung W. K. et al. Enteric involvement of severe acute respiratory syndrome-associated coronavirus infection //Gastroenterology. 2003. - T. 125. - №. 4. - C. 1011-1017.

20. Dimitrov D. S. The secret life of ACE2 as a receptor for the SARS virus //Cell. - 2003. - T. 115. - №. 6. - C. 652-653.

21. Oudit G. Y. et al. SARS-coronavirus modulation of myocardial ACE2 expression and inflammation in patients with SARS // European journal of clinical investigation. - 2009. - T. 39. - №. 7. - C. 618-625.

22. Kissling S. et al. Collapsing glomerulopathy in a COVID-19 patient //Kidney International. - 2020.

23. Кожиева М. X и др. Кишечная микробиота человека и рассеянный склероз //Журнал неврологии и психиатрии им. СС Корсакова. Спецвыпуски. - 2017. - Т. 117. - №. 10. - С. 11-19.

24. Keely S. et al. Activated fluid transport regulates bacterial-epithelia interactions and significantly shifts the murine colonic microbiome //Gut microbes. - 2012. - T. 3. - №. 3. - C. 250-260.

25. Dumas $\mathrm{A}$. et al. The role of the lung microbiota and the gut-lung axis in respiratory infectious diseases //Cellular microbiology. 2018. - T. 20. - №. 12. - C. e12966. 